\title{
Epstein-Barr virus infection of renal proximal tubule cells: possible role in chronic interstitial nephritis
}

\author{
Joanne L. Becker, ${ }^{1}$ Frederick Miller, ${ }^{1}$ Gerard J. Nuovo, ${ }^{1}$ Christine Josepovitz, ${ }^{2}$ \\ William H. Schubach, ${ }^{3}$ and Edward P. Nord ${ }^{2}$ \\ ${ }^{1}$ Department of Pathology, and \\ ${ }^{2}$ Department of Medicine, Division of Nephrology, School of Medicine, State University of New York at Stony Brook, \\ Stony Brook, New York 11794, USA \\ ${ }^{3}$ Department of Medicine, Division of Oncology, Veterans Administration Puget Sound Health Care System, \\ University of Washington School of Medicine, Seattle, Washington 98108, USA
}

Address correspondence to: Edward P. Nord, Department of Medicine, Division of Nephrology, School of Medicine, HSC T-15 Rm-020, State University of New York at Stony Brook, Stony Brook, New York 11794, USA. Phone: (516) 444-1617; Fax: (516) 444-6174; E-mail: enord@mail.som.sunysb.edu.

\begin{abstract}
Chronic interstitial nephritis frequently accompanies renal diseases of different etiologies. Far less common is the entity of primary interstitial nephritis wherein the glomerular and vascular structures of the kidney are not the primary focus of the disease process. Using in situ hybridization and the polymerase chain reaction, we detected DNA from the Epstein-Barr Virus (EBV) exclusively in renal tissue of patients with the idiopathic variety of chronic interstitial nephritis. The EBV genome, but not that of cytomegalovirus or adenovirus, was detected primarily in renal proximal tubule cells. Furthermore, the CD21 antigen, which serves as the receptor for EBV in B lymphocytes, was detected by immunocytochemistry primarily on proximal tubule cells and was markedly upregulated in the EBVinfected tissue. Western blot analysis of primary cultures of normal proximal tubule cells identified a $140-\mathrm{kDa}$ protein, confirming the expression of the CD21 antigen. Colocalization experiments using proximal and distal tubule markers confirmed that EBV DNA and the CD21 antigen are found primarily in proximal tubule cells. EBV infection of renal proximal tubular cells may participate in evoking a cellular immune response that results in a damaged renal interstitium.
\end{abstract}

J. Clin. Invest. 104:1673-1681 (1999).

\section{Introduction}

Renal tubulo-interstitial injury occurs either as a primary process or as an important secondary process that accompanies a variety of underlying glomerulopathies, renal vascular disease, or systemic entities involving the kidney, as in the case of diabetes mellitus. With regard to primary interstitial nephritis, the injury pattern may be predominantly inflammatory or fibrotic. The inflammatory process may resolve without sequelae or progress to a fibrotic pattern that culminates in renal insufficiency. The factors initiating the primary process and the factors leading to progression from acute inflammation to chronic fibrosis are poorly understood.

Viral infection of renal tissue is one potential proinflammatory factor that has been largely ignored. Prompted by a report that Epstein-Barr virus (EBV) DNA was detected by in situ hybridization in the epithelial cells of salivary gland specimens from patients with Sjögren's Syndrome (1), we explored whether renal epithelial cells might also contain EBV genomes. The study was then expanded to include other forms of primary interstitial nephritis. These observations form the basis for the current report in which we propose that EBV infection of renal proximal tubule cells plays an important role in the initiation and/or progression of the inflammatory and injury pattern seen in primary interstitial nephritis.
EBV is a ubiquitous human herpes virus that causes infectious mononucleosis (2) and is strongly implicated in the pathogenesis of several human malignancies (3-5). The cellular receptor for EBV is the CD21 molecule, which is expressed in both lymphoid and epithelial cells (6-8). B lymphocytes are the usual site of latent infection, whereas epithelial cells usually become productively infected. In these latently infected cells, the EBV genome is maintained as a multicopy episome, but no virus is produced. These cells express a restricted subset of viral genes: 6 nuclear proteins, 2 membrane proteins, and 2 classes of RNA polymerase III transcripts (9-12). Immunologically competent hosts control latent EBV infection through HLA-restricted cytotoxic effectors that recognize a number of the latent-phase proteins as antigens. The potential role of EBV as a factor underlying chronic interstitial nephritis has not been explored previously.

\section{Methods}

Patient selection and preparation of kidney sections. Renal biopsies diagnosing primary interstitial nephritis (tubulointerstitial nephritis) were obtained from the files of the Department of Pathology, University Medical Center, State University of New York at Stony Brook. Tissues had been routinely fixed overnight in $10 \%$ buffered formalin, dehydrated in alcohol, and then 
embedded in paraffin. They were also snap frozen in liquid nitrogen. Samples were sectioned at $2-\mu \mathrm{m}$ thickness. Histologic examination of each tissue preparation was performed with hematoxylin and eosin (H\&E), periodic acid Schiff, Jones' silver methenamine, and trichrome stains. The histologic criteria for interstitial nephritis included an interstitial infiltrate of mononuclear cells (with or without fibrosis or edema) and varying degrees of tubular atrophy (with little or no glomerular or vascular disease). The diagnosis was also based on the electron microscopic and immunological analyses done on each biopsy. All biopsies were deemed adequate for analysis based on the number of glomeruli $(>10)$ in the section. Interstitial nephritis samples from patients with HIV-1 disease or in renal transplant recipients were excluded from this study. Over an 8-year period, 17 suitable cases were identified. The patients ranged in age from 11 to 74 years old, 10 were male, and 7 were female (Table 1). Also analyzed were 11 random renal biopsies that lacked the histologic features of interstitial nephritis (Table 1); instead,

Table 1

Clinical and pathological findings of patients with renal disease

\begin{tabular}{|c|c|c|c|}
\hline $\begin{array}{l}\text { Category } \\
\text { patient \# }\end{array}$ & Age (yr) & Sex & Histology \\
\hline \multicolumn{4}{|c|}{ Interstitial nephritis, idiopathic ${ }^{A}$} \\
\hline 1 & 48 & M & INB, chronic \\
\hline 2 & 50 & M & IN, chronic ${ }^{\mathrm{C}}$ \\
\hline 3 & 67 & M & IN, chronic \\
\hline 4 & 70 & $\mathrm{~F}$ & IN, chronic \\
\hline 5 & 43 & $\mathrm{~F}$ & IN, chronic ${ }^{\mathrm{C}}$ \\
\hline 6 & 61 & M & IN, chronic \\
\hline 7 & 46 & $\mathrm{~F}$ & IN, chronic \\
\hline 8 & 32 & M & IN, acute \\
\hline 9 & 74 & $\mathrm{~F}$ & IN, chronic \\
\hline 10 & 64 & M & IN, chronic \\
\hline 11 & 11 & $\mathrm{~F}$ & IN, acute \\
\hline \multicolumn{4}{|c|}{ Interstitial nephritis, drug-related ${ }^{\mathrm{D}}$} \\
\hline 12 & 49 & M & $\mathrm{IN}$, acute \\
\hline 13 & 69 & $\mathrm{~F}$ & IN, chronic \\
\hline 14 & 37 & $\mathrm{~F}$ & IN, acute \\
\hline 15 & 66 & M & IN, chronic \\
\hline 16 & 38 & M & IN, chronic \\
\hline \multicolumn{4}{|c|}{ Interstitial nephritis, infectious } \\
\hline 17 & 38 & M & IN, acute (Hantavirus) \\
\hline \multicolumn{4}{|l|}{ Controls } \\
\hline 18 & $2 \mathrm{mo}$ & M & Chronic pyelonephritis \\
\hline 19 & 21 & M & Thin loop syndrome \\
\hline 20 & 32 & M & Amyloid deposition \\
\hline 21 & 47 & $M$ & Focal glomerulosclerosis \\
\hline 22 & 2 & M & Nil disease \\
\hline 23 & 73 & M & Arteriosclerosis \\
\hline 24 & 23 & $\mathrm{~F}$ & Nil disease \\
\hline 25 & 28 & M & Acute tubular necrosis \\
\hline 26 & 62 & M & Ischemic renal disease \\
\hline 27 & 19 & $M$ & Focal glomerulosclerosis \\
\hline 28 & 58 & $\mathrm{~F}$ & Diffuse glomerulosclerosi \\
\hline
\end{tabular}

Aldiopathic was defined by the absence of any known risk factor including administration of a drug associated with interstitial nephritis. ${ }^{B} \mathrm{IN}$, interstitial nephritis. 'Sjögren's disease. ${ }^{D}$ Drug-related indicates that these patients had received medication known to be associated with interstitial nephritis predating the clinical disease. they primarily demonstrated features of glomerular disease ( 7 cases), vascular disease ( 2 cases), or tubular disease ( 2 cases).

For the molecular analysis, 2 tissue sections $(5 \mu \mathrm{m})$ were mounted side by side on a microscope slide coated with 3-amino-propyl-triethoxysilane. Before experimentation, sections were washed with a buffered saline solution and dehydrated in successive alcohol washes of increasing concentration according to the manufacturer's instructions (Enzo Biochem, Farmingdale, New York, USA). Microscope slides were then dried at $37^{\circ} \mathrm{C}$ for 5 minutes.

In situ bybridization. Tissues were analyzed for DNA sequences homologous to EBV by in situ hybridization (ISH) using the PathoGene DNA probe pack (Enzo Biochem) and protocols described previously by this laboratory (13-15). In parallel experiments, tissues were analyzed for DNA sequences homologous to adenovirus and cytomegalovirus (CMV) to elucidate the specificity of the observation. The EBV probe was prepared by nick translation of the $2.68-\mathrm{kb}$ BamHI/V internal repeat fragment of the EBV genome (16). This sequence is repeated $11-14$ times in the various EBV strains. The CMV probe was prepared from fragments of the CMV Towne strain that include $30-31 \mathrm{~kb}$ of DNA, encompassing approximately $20 \%$ of the CMV genome (17). The adenovirus probe was prepared from genomic adenovirus type 5 DNA and detects this type as well as types 4, 7, 11, 20, 40, and 41 (18). Tissue and the biotin-labeled probe DNA in hybridization buffer $(500 \mathrm{ng} / \mathrm{mL}$ in $50 \%$ formamide and $150 \mathrm{mM} \mathrm{NaCl}$ ) were simultaneously denatured at $95^{\circ} \mathrm{C}$ for 8 minutes. ISH proceeded at $37^{\circ} \mathrm{C}$ for $30-45$ minutes. After successive washes (following the manufacturer's instructions), the alkaline phosphatase-nitroblue tetrazolium/bromo chloro indolyl phosphate (NBT/BCIP) colorimetric detection method was used to detect the biotin-labeled nucleic acid probes, and nuclear fast red was used for counterstaining (Enzo Biochem). The alkaline phosphatase-NBT/BCIP-based colorimetric detection method results in a purple-blue precipitate at the site of hybridization, whereas the counterstain imparts a pale pink color to both the nuclei and cytoplasm. The positive control probe was biotinylated DNA derived from human repetitive Alu sequence, and the negative control probe was biotinylated plasmid vector DNA (Intergen, Gaithersburg, Maryland, USA). The EBV positive control was a Burkitt's lymphoma cell line (BL41/B958), which contains the virus, and the negative control was EBV-negative Ramos cells. Positive and negative controls for CMV were human CMV-infected and -noninfected human fibroblasts, respectively, and human placenta. Positive and negative controls for adenovirus were human adenovirus-5-infected and -noninfected HeLa cells, respectively, as well as human lung tissue. Viral analysis by ISH was done without knowledge of the clinical or pathological results.

DNA extraction, solution PCR, and Southern blot analysis. To verify both the positive and negative observations 
for detection of EBV DNA by ISH, all tissues were analyzed for EBV DNA using the PCR. For this purpose, total cellular DNA was extracted from the formalinfixed, paraffin-embedded biopsy tissue (19). In each experiment, a negative control (tissue and water) and a positive control (Burkitt lymphoma cells) were routinely included. A GeneAmp PCR (Perkin-Elmer Corp., Norwalk, Connecticut, USA) kit was used to amplify the viral DNA. Primers for amplification of EBV DNA were 5'-CCA GAG GTA AGT GGA CTT-3' (sense) and 5'-GAC CGG TGC CTT CTT AGG-3' (antisense) (20). Fifty cycles of PCR amplification were performed under conditions described previously (13): $94^{\circ} \mathrm{C}$ for 1 minute, $69^{\circ} \mathrm{C}$ for 1 minute, and $72^{\circ} \mathrm{C}$ for 2 minutes. Additional Taq polymerase and nucleotide substrates were added after 25 cycles. The amplified DNA products were size fractionated on a $1.0 \%$ agarose gel. Southern blot hybridization was performed using an internal ${ }^{32} \mathrm{P}$ end-labeled probe TTC TGC TAA GCC CAA C (20), using methods described previously (13). The amplified product was $124 \mathrm{bp}$. DNA bands were revealed by autoradiography at $-70^{\circ} \mathrm{C}$ overnight.

Immunohistochemistry. Immunocytochemical staining for $\mathrm{CD} 21$ was carried out on acetone-fixed, $5-\mu \mathrm{m}$ isopentane-liquid nitrogen frozen sections according to a procedure adapted from methods described previously by this laboratory (21). Optimal dilutions of the first antibody, determined by checkerboard titration, were incubated with the tissue at room temperature for $60-90$ minutes followed by 3 rinses in buffered saline at $3^{\circ}-5^{\circ} \mathrm{C}$. The alkaline phosphatase-coupled secondary antibody was then applied for 60 minutes under identical conditions. After 3 final rinses, the slides were developed and examined by light microscopy. Nonspecific binding of secondary antibody was determined by omitting the primary antibody (vehicle only) from the initial incubate. An irrelevant antibody ensured specificity. All studies were blinded. Antibodies used were of mouse monoclonal origin directed against CD21 (CB2, HB5, and 10B1a; DAKO, Carpinteria, California, USA, and/or Becton-Dickinson Immunocytometry Systems, San Jose, California, USA; and HB5 was obtained courtesy of Dr. Neil Cooper, Scripps Institute, La Jolla, California, USA). Cell culture and metabolic labeling of cells. Primary cultures of human proximal tubule cells were established based on the methodology used in the rabbit model (22, 23). Normal renal tissue from nephrectomy specimens obtained during the course of cancer surgery was used as source material. Verification of proximal tubule origin was performed as described previously by our laboratory (24) and others (25). Cultures were maintained in a defined medium composed of $1: 1(\mathrm{vol} / \mathrm{vol})$ mixture of DMEM and Ham's F12 medium supplemented with insulin $(5 \mu \mathrm{g} / \mathrm{mL})$, transferrin $(5 \mu \mathrm{g} / \mathrm{mL})$, hydrocortisone $(50 \mathrm{nM})$, triiodothyronine $(5 \mathrm{pM})$, and sodium selenate $(10 \mathrm{nM})$, and then perpetuated in a humidified incubator at $37^{\circ} \mathrm{C}$ in $95 \%$ air $-5 \% \mathrm{CO}_{2}$ (culture medium, $\mathrm{pH}$ 7.3). Media were exchanged at 48- to 72-hour intervals, and cells were propagated through $8-10$ passages.
For comparative purposes, human glomerular mesangial cells were used. Cells were purchased from Clonetics (San Diego, California, USA) and maintained in culture according to the manufacturer's instructions. BL41/95 cells, a Burkitt lymphoma cell line, was a gift from G. Lenoir (International Association of Cancer Registries, Lyon, France) and maintained in a complete growth medium composed of RPMI 1640 supplemented with $10 \%$ heat-inactivated FBS.

Before experimentation, cells were incubated in a methionine- and cystine-free medium overnight, and on the day of experimentation were pulsed with $1 \mathrm{mCi}$ of $\left[{ }^{35} \mathrm{~S}\right]$ methionine/flask for 4 hours.

Immunoprecipitation and SDS-PAGE. Confluent monolayers of $\left.{ }^{35} \mathrm{~S}\right]$ methionine-labeled human proximal tubule cells, mesangial cells, and cultured Burkitt lymphoma (B41/95) cells were extensively washed, lysed, and then the cell lysates were immunoprecipitated with the HB5 CD21 mAb using protocols reported previously by this laboratory (21). Matched aliquots were subjected to SDS-PAGE in a $7.5 \%$ gel that was subsequently dried on a gel slab drier (Bio-Rad Laboratories Inc., Hercules, California, USA) and subjected to autoradiography at $-70^{\circ} \mathrm{C}$ overnight. Molecular weight markers were used to determine the size of the detected band. Relative densities of the protein bands were determined with a GS-670 imaging densitometer and Molecular Analyst PC software program (Bio-Rad Laboratories Inc.). One of 4 similar autoradiograms obtained from different passaged cultures is shown.

Lectin histochemistry. Two different peroxidase-labeled lectins were used to identify proximal and distal tubule elements in sectioned pathological tissue. Phaseolus vulgaris erythroagglutinin (PHA-E) was used as a proximal tubule marker, and Arachis hypogaea (AH) was used as a distal tubule marker using established methods (26). Briefly, deparaffinized sections were treated with $1.25 \%$ $\mathrm{H}_{2} \mathrm{O}_{2}$ in methanol for 30 minutes to block endogenous peroxidase activity. Sections were subsequently incubated with each peroxidase-labeled lectin (PHA-E $1 \mu \mathrm{g} / \mathrm{mL}$; $\mathrm{AH} 10 \mu \mathrm{g} / \mathrm{mL}$ ) for 60 minutes at room temperature, and the reactions were developed with diaminobenzidine. In the localization and overlay experiments, sections were first subjected to immunohistochemistry or ISH followed by lectin histochemistry.

Materials. DMEM, Ham's F12 medium, RPMI 1640, and FBS were purchased from GIBCO BRL (Grand Island, New York, USA). Protein A-Sepharose CL-4B beads were purchased from Pharmacia Biotech Inc. (Piscataway, New Jersey, USA), and rainbow molecular weight markers from Amersham Life Sciences Inc. (Arlington Heights, Illinois, USA). Electrophoretic grade reagents used for SDS-PAGE were obtained from BioRad Laboratories Inc. $\left.{ }^{35} \mathrm{~S}\right]$ Methionine $(>1,000$ $\mathrm{Ci} / \mathrm{mmol}$ ) was purchased from ICN Radiochemicals Inc. (Irvine, California, USA). Peroxidase-labeled lectins PHAE and AH were purchased from Sigma Chemical Co. (St. Louis, Missouri, USA). All standard chemicals used were purchased at the highest commercial grade available. 
Figure 1

Chronic interstitial nephritis (case no. 5 ) showing interstitial fibrosis and a predominantly lymphocytic infiltrate. Atrophic and dilated tubules are noted (a). Some cytologic atypia is seen in a proximal convoluted tubule (b). H\&E stain. (a) $\times 25$; and (b) $\times 40$

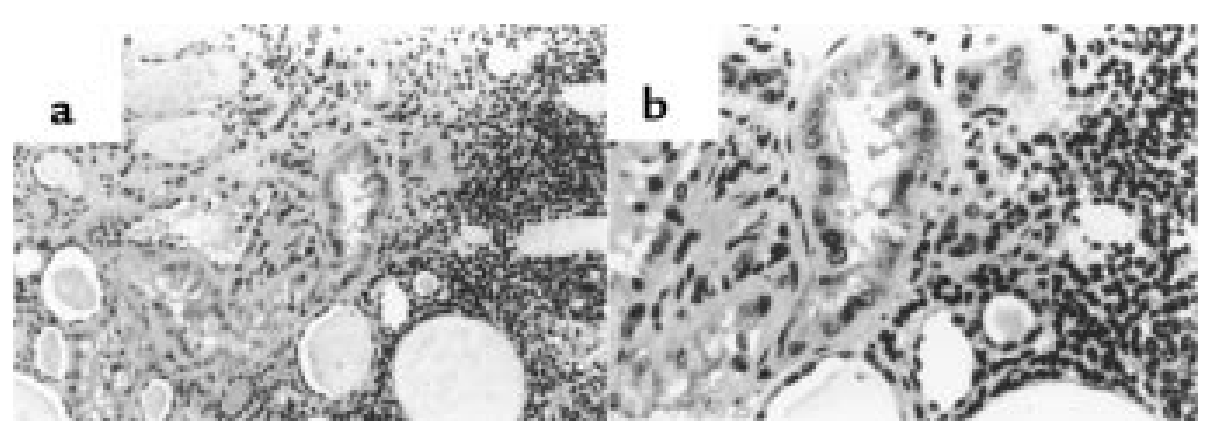

\section{Results}

Analysis of renal biopsy material by light microscopy. Renal biopsy material obtained from 28 patients was analyzed in this study. Of these, 17 had the histologic features of interstitial nephritis; the remaining 11 comprised a variety of other pathological lesions, and served as controls. These data are summarized in Table 1. The primary alteration in specimens with interstitial nephritis was an intertubular infiltrate of mononuclear cells. The acute process was associated with edema and congestion, whereas chronicity was marked by collagen deposition and tubular atrophy. In the 2 patients with Sjögren's disease, the inflammatory cells were mostly lymphocytes, whereas in some patients with a drug reaction, mostly eosinophils were evident. However, in most instances, the etiology of the inciting event could not be ascertained on the basis of the histologic changes alone.

The hallmark features of chronic interstitial nephritis are illustrated in an H\&E-stained section (Figure 1) obtained from the index case (case no. 5). The patchy infiltrate of primarily mononuclear cells within the interstitium can be readily appreciated (Figure 1a). "Thyroidization" of the renal cortex is in keeping with a chronic process (Figure 1a). The epithelial cells of the proximal tubule are atypical, with enlarged nuclei and prominent nucleoli present (Figure 1b). Distal tubular epithelial cells were generally less involved in the pathologic process. Changes seen in the glomeruli and vascular elements were in keeping with the degree of renal dysfunction (data not shown).

\section{Table 2}

Correlation between clinical and pathological findings and EBV DNA detection by ISH and PCR

\section{Category} EBV DNA by ISH EBV DNA by PCR

Interstitial nephritis, idiopathic ${ }^{A}$

$\begin{array}{lcc}\text { Chronic } & 9 / 9 & 9 / 9 \\ \text { Acute } & 0 / 2 & 0 / 2 \\ \text { Interstitial nephritis drug-related } & \\ \text { Chronic } & & \\ \text { Acute } & 0 / 3 & 0 / 3 \\ \text { Interstitial nephritis, infectious }^{\mathrm{A}} & 0 / 2 & 0 / 2 \\ \text { Controls }^{\mathrm{A}} & 0 / 1 & 0 / 1 \\ & 0 / 11 & 0 / 11\end{array}$

AAs defined in Table 1.
As summarized in Table 1, the parameters for chronic interstitial nephritis (outlined previously), were met in 12 specimens. Within these 12 , no etiologic factor could be determined from the archival records of 7 patients (nos. 1, 3, 4, 6, 7, 9, and 10), whereas 2 patients met the criteria for Sjögren's disease (nos. 2 and 5). These 9 specimens were categorized as chronic idiopathic interstitial nephritis. In 3 patients (nos. 13, 15, and 16), chronic interstitial nephritis could be associated with exposure to a specific drug. The criteria for acute interstitial nephritis, as detailed earlier, were met in 5 specimens. Of these, 2 were associated with drug exposure (nos. 12 and 14), 1 was associated with an infectious process (no. 17), and in 2, no etiologic agent could be determined (nos. 8 and 11). The control specimens (nos. 18-28) included a variety of primary glomerular, vascular, and other renal diseases, where the brunt of the pathologic process is not borne by the interstitial compartment.

Analysis of renal biopsy material by ISH. The 28 samples were analyzed for sequences homologous to EBV, adenovirus, and CMV DNA by ISH. As positive controls, formalin-fixed placental tissue was probed for CMV (Figure 2a), formalin-fixed lung tissue was probed for adenovirus (Figure 2b), and an EBV-negative and -positive Burkitt's lymphoma cell line served both as negative and positive controls for EBV (Figure 2, c and d). Each gave hybridization signals with the appropriate probe without evidence of cross reactivity with the other viral probes or the negative plasmid probe under high-stringency conditions (Figure 2). Of the 17 tissues with interstitial nephritis (acute and chronic, Table 1), 9 contained EBV DNA demonstrable by ISH. The results from 2 representative specimens are shown in Figure 3. The plasmid control is shown in Figure 3a. The index case (Figure $3 \mathrm{~b}$ ) illustrates localization of the viral DNA to the proximal convoluted tubular cells (purple). This can be better appreciated at a higher magnification (Figure 3c). A second example (case no. 7 , Table 1) illustrates the same features in which viral DNA is confined exclusively to proximal tubule epithelial cells (Figure 3d). In all fields visualized, sequences homologous to EBV DNA were absent from any other cellular component including the infiltrating lymphocytes and plasma cells. In 1 case, the distal convoluted tubular cells were involved (data not shown), but clearly to a much lesser extent. Neither adenoviral nor CMV DNA was detectable in any tissue. When these results 


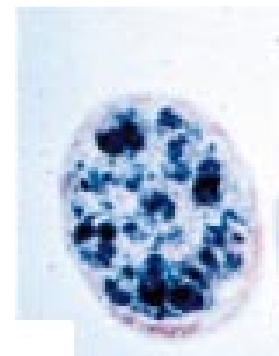

a

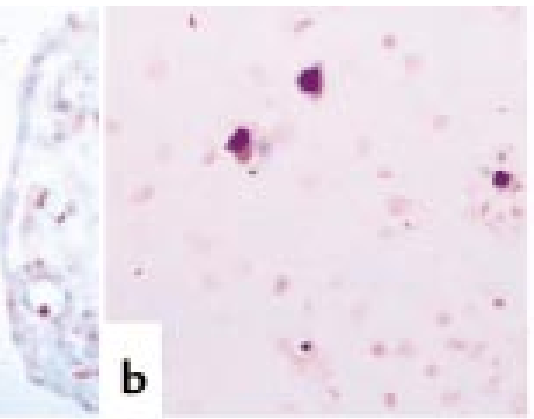

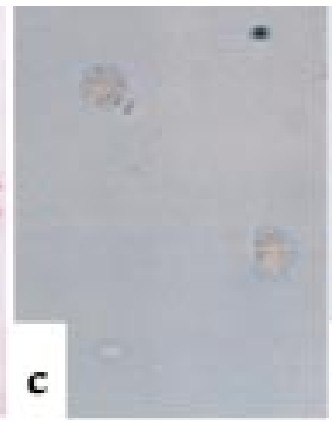

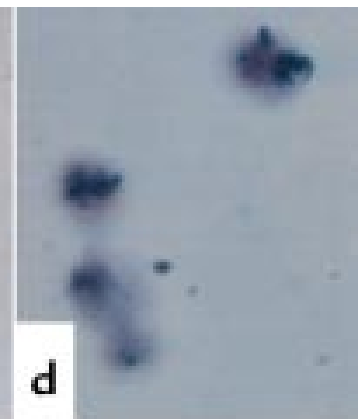

Figure 2

ISH controls for CMV DNA in placenta (a), adenovirus DNA in lung (b), plasmid vector pBR322 DNA in EBV-negative Burkitt's lymphoma cells (c), and EBV DNA in EBV-positive Burkitt's lymphoma cells (d). The positive dark signal (a, b, and d) represents the action of streptavidin-alkaline phosphatase conjugate on NBT/BCIP. The plasmid vector pBR322 does not give a signal. Nuclear fast red counterstain. (a and $\mathbf{b}) \times 40$; and $(\mathbf{c}$ and $\mathbf{d}) \times 100$.

were correlated with the H\&E data described in Table 1 , the 9 EBV containing tissues with interstitial nephritis corresponded to the cases of chronic idiopathic interstitial nephritis (Table 2). The remaining 8 tissues that had pathologic features of either acute interstitial nephritis associated with drugs ( 2 cases), infection (1 case), or an unknown agent (2 cases), or chronic interstitial nephritis attributed to medications associated with this entity ( 3 cases) were all negative for EBV DNA by ISH, as were all 11 control tissues associated with a broad spectrum of renal diseases.
Detection of EBV DNA in renal biopsy material by solution $P C R$. To determine whether the EBV-negative tissues may have contained EBV DNA in amounts below the detection threshold of the ISH assay, solution PCR was performed on tissue obtained from each specimen using EBV-specific primers. Each of the 9 tissues positive by ISH for EBV DNA were positive by PCR (Table 2). Representative samples are depicted in Figure 4, lanes a-d (case nos. 1, 3, 5, and 9). Lanes $f$ and $g$ (Figure 4) represent a positive control (EBV-positive lymphoma in a patient with AIDS) and a negative (vehicle) control,
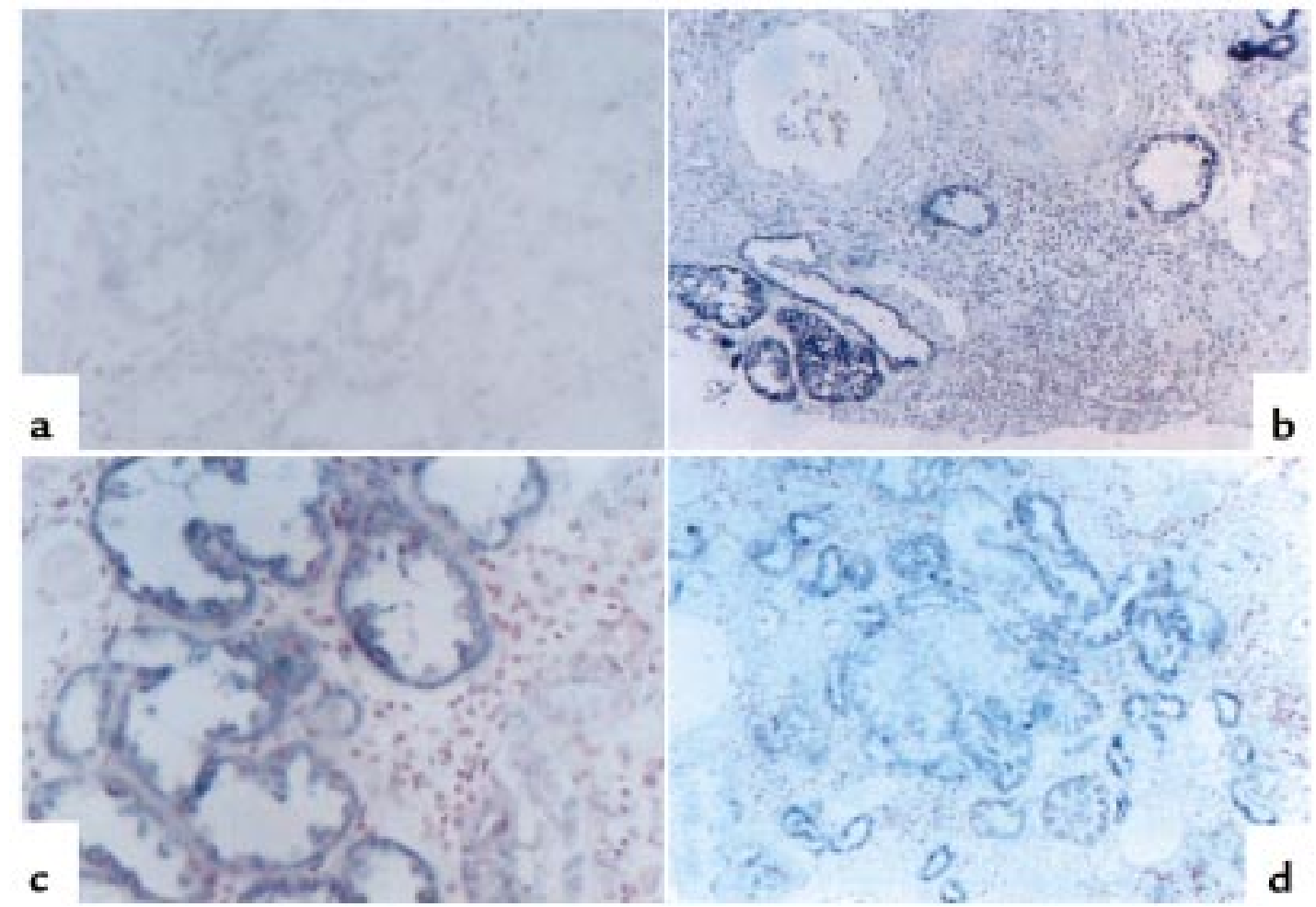

Figure 3

ISH of renal cortex using a probe for EBV DNA. (a) Failure to stain using the plasmid probe. (b and c) Index case (no. 5), revealing the localization of the viral DNA to the proximal convoluted tubule cells (purple). Second case (no. 7) in (d) shows the same features with staining confined to the proximal tubules. ( $\mathbf{a}$ and $\mathbf{c}) \times 40$; ( $\mathbf{b}$ and $\mathbf{d}) \times 10$. 


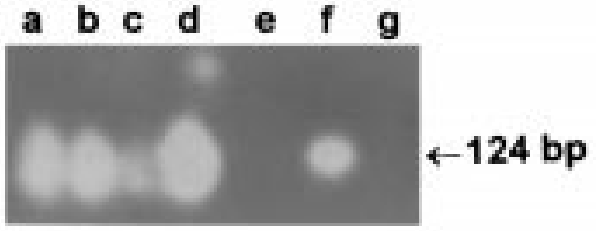

Figure 4

Solution PCR analysis of renal biopsy material. Amplified EBV DNA was detected using the internal ${ }^{32}$ P-labeled probe in 4 renal biopsies of idiopathic chronic interstitial nephritis (lanes a-d), but not in a case of acute drug-related interstitial nephritis (lane e). Lane $\mathbf{f}$ is from an EBV-positive lymphoma from a patient with AIDS, and lane $\mathbf{g}$ is the negative water control.

respectively. EBV DNA was not detected by PCR in any other specimen where interstitial nephritis (either acute or chronic) had been diagnosed by light microscopic criteria (Table 2). A representative sample (case no. 13) is depicted in lane e (Figure 4). PCR did not detect EBV DNA in 11 consecutive renal biopsies from patients with either glomerular, tubular, or vascular disease (Table 2). In aggregate, EBV DNA was detected by 2 independent assays, and was found exclusively in tissue that had light microscopic features of chronic interstitial nephritis where no inciting agent could be identified.

Detection of the CD21 antigen. Our observed selective infection of proximal convoluted tubule cells by EBV raised the possibility of preferential localization of an EBV receptor on cells of this nephron segment. Because the CD21 antigen has been identified as a receptor for EBV in other tissues $(8,27)$ immunohistologic analysis for CD21 was performed on this tissue. In preliminary experiments, renal tissue from 3 specimens without evidence of interstitial nephritis was analyzed to determine whether the receptor is expressed before the development of disease. Epitopes reactive against CD21 were detected in each of these tissues and localized to the proximal convoluted tubule cells (Figure 5a). These were very faint, and the number of such receptors (judged by crude qualitative estimates) were markedly increased in cases with idiopathic interstitial nephritis, as exemplified by the index case (Figure 5b). Because the detection of CD21 on epithelial cells has been a source of controversy, we used several antisera (specified in the Methods section), and all gave comparable results.

Although the immunostaining data confirmed the presence of the CD21 antigen primarily in proximal tubule cells, information regarding the nature of the peptide identified was not forthcoming. To establish that this antigen represented the CD21 molecule, primary cultures of human proximal tubule cells derived from healthy tissue were subjected to Western blotting as outlined in Methods. (Cells were obtained from a nephrectomy specimen performed for cancer surgery.) Cultured human mesangial cells and BL41/B95 lymphocytes were included as a negative and positive control, respectively. As shown in Figure 6, the characteristic $140-\mathrm{kDa}$ band defining the CD21 antigen was detected in proximal tubule cells. A band of identical $M_{\mathrm{r}}$ was detected in BL 41/95 cells as expected, whereas none was found in mesangial cells. These data confirm the immunohistochemical stains that indicated the presence of the CD21 antigen on proximal tubule cells.

Colocalization of CD21 and EBV DNA in proximal tubule cells. To confirm that EBV DNA and CD21 were indeed detected primarily in proximal tubule cells, colocalization or overlay experiments were performed on tissue from an individual with chronic idiopathic interstitial nephritis, and representative photomicrographs are depicted in Figure 7. Lectin histochemistry was used to identify proximal and distal tubule elements $(26,28)$. Peroxidase-labeled PHA-E stains proximal tubule cells (Figure 7a), whereas AH stains distal tubule cells (Figure 7b). Immunohistochemical staining for CD21 parallels the proximal tubule pattern as shown in Figure $7 c$, although some staining in distal tubules is present. Sequential immunohistochemical staining for CD21, followed by lectin histochemistry for distal or proximal tubule cells showed that most
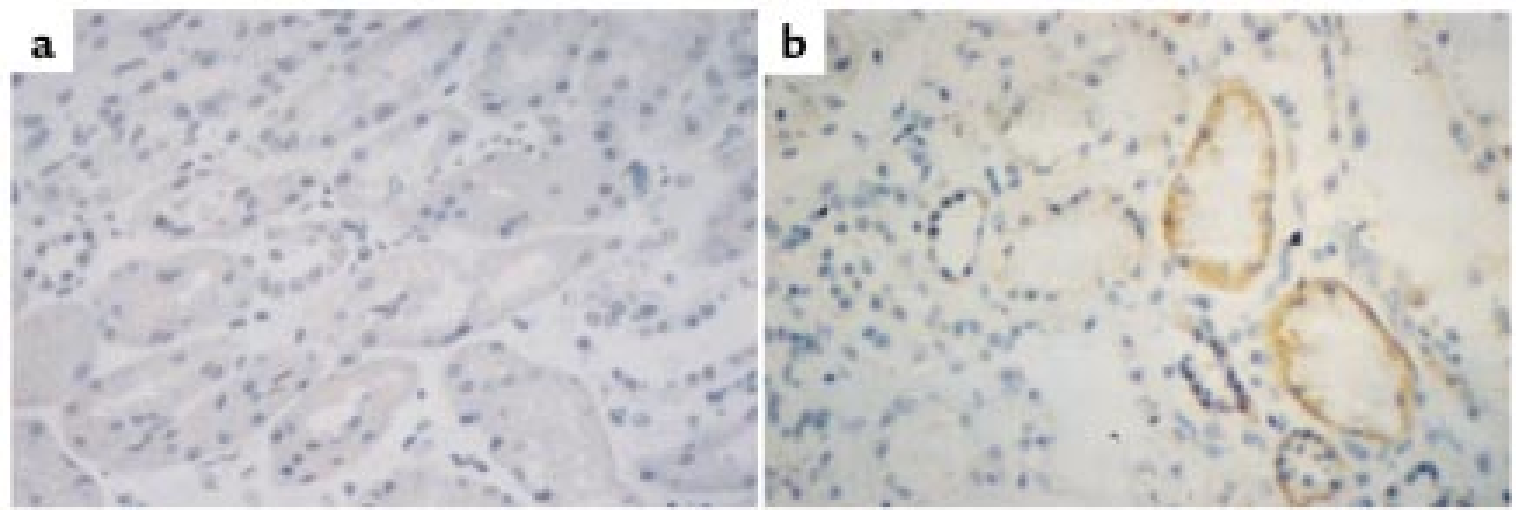

Figure 5

Immunohistochemical detection of CD21, an EBV receptor, in control material (a), and case no. 5 (b). The reddish-brown stain represents the action of the peroxidase conjugate on amino ethyl carbazole. In the absence of primary antibody or the presence of an irrelevant antibody, no staining was observed (data not shown). Hematoxylin counterstain, $\times 40$. 


\section{Figure 6}

Detection of CD21 by immunoprecipitation and SDS-PAGE. Cultured human proximal tubule cells (HPTC), human mesangial cells (MES), and EBV-infected Burkitt's lymphoma cells (BL $41 / 95$ ) were $\left[{ }^{35} \mathrm{~S}\right]$ methionine labeled. Cells were lysed and immunoprecipitated with the HB5 CD21 mAb, and then lysates were subjected to SDS-PAGE on a 7.5\% gel. Dried gels were autoradiographed at $-70^{\circ} \mathrm{C}$ overnight, before development. One of 4 similar autoradiograms is shown.

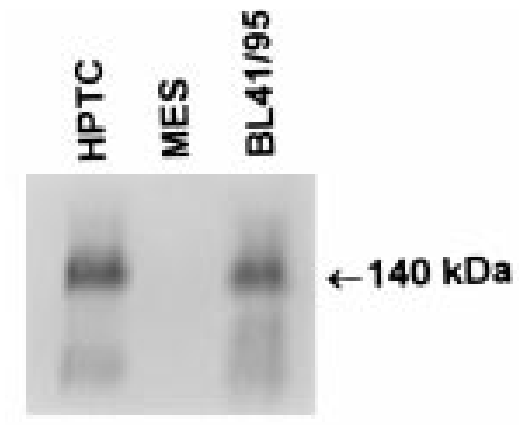

CD21-staining cells do not colocalize with the distal tubule marker (Figure 7d), instead they invariably colocalize with the proximal tubule marker (Figure 7e). Finally, ISH for EBV DNA, followed by lectin histochemistry with the proximal tubule marker, demonstrates overlay of the ISH signal by the proximal tubule cell marker (Figure 7f). These data confirm that EBV DNA and the CD21 antigen are found primarily in proximal tubule cells in chronic interstitial nephritis of the idiopathic variety.

\section{Discussion}

The observation of primary importance to this study is the finding of EBV genomes exclusively in renal tissue of patients with the idiopathic variety of chronic interstitial nephritis, and the lack of these genomes in those patients with a wide variety of primary glomerular and vascular diseases (Tables 1 and 2). EBV genomes were detected in the proximal tubular epithelial cells by ISH (Figure 3). The absence of EBV DNA in drug hypersensitivity-related interstitial nephritis was confirmed by the more sensitive PCR assay (Figure 4), establishing the specificity of the observation. Importantly, EBV DNA was not detected in any of the infiltrating mononuclear cells (Figure 3),

\section{Figure 7}

Colocalization of CD21 and EBV DNA to proximal tubule cells in chronic idiopathic interstitial nephritis. (a) Treatment with peroxidase-labeled PHA-E lectin and a diaminobenzidine development system identifies proximal tubules as deep brown structures. (b) AH lectin identifies distal tubules by their yellowbrown appearance. (c) Immunohistochemical detection of CD21 using a specific antibody coupled to alkaline phosphatase with nitroblue tetrazolium as the detection reagent gives a purple color. ( $\mathbf{d}$ and $\mathbf{e}$ ) Sequential staining for CD21 by immunohistochemistry and lectin histochemistry for distal tubule (d) and for proximal tubule (e) identification. (f) ISH for EBV DNA followed by lectin histochemistry for proximal tubule identification. All sections are counterstained with nuclear fast red. G: glomerulus; PT: proximal tubule; DT: distal tubule. $(\times 200)$. and DNA from both CMV and adenovirus was absent from any of the tissues examined. Furthermore, expression of the CD21 antigen was detected by immunocytochemistry only on proximal tubule cells, and its expression was enhanced in the EBV-infected cells (Figure 5). Western blot analysis performed on healthy proximal tubule cells identified a $140-\mathrm{kDa}$ protein (Figure 6). Because the $B 2$ antibody used in these studies recognizes an epitope of CD21, which is also the EBV recep-

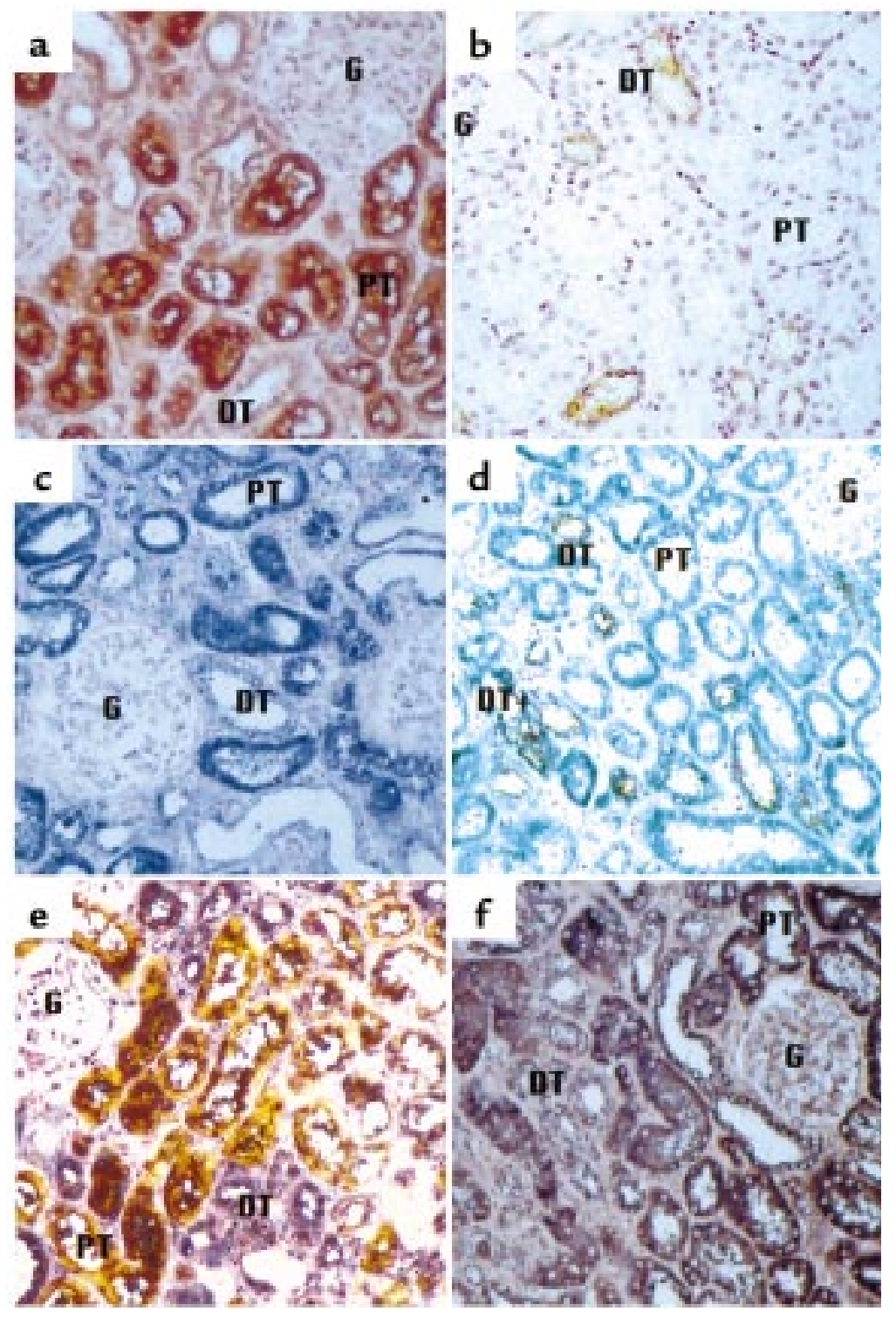


tor, the specificity of EBV infection in the tissue samples studied is readily explained. Finally, colocalization experiments incorporating lectin histochemistry as a marker of proximal and distal tubule elements confirmed that EBV DNA and the CD21 antigen are detected primarily in proximal tubule cells.

Although the current observation does not establish cause and effect, it is striking that EBV genomes were detected exclusively in biopsy specimens from patients with the idiopathic variety of chronic interstitial nephritis; it is also important to note that in the kidney, the CD21 antigen is expressed exclusively on the proximal tubule cell. The EBV receptor, CD21, also serves as the receptor for the $\mathrm{C} 3 \mathrm{~d}, \mathrm{~g}$ component of complement (6). It consists of an extended extracellular $\mathrm{NH}_{2}$-terminal domain that contains $15-16$ short consensus repeats, each comprising 60-75 amino acids, and smaller transmembrane and intracellular domains (29-31). EBV binds to CD21 by contact between a peptide on the viral glycoprotein gp350/220 and short consensus repeats 1 and 2 of CD21.

Previous studies have identified a $140-\mathrm{kDa}$ immunoreactive protein recognized by the HB-5a antiCD21 antibody on the surface of keratinocytes and other epithelial cells (7). This same antibody also recognized a protein of $195 \mathrm{kDa}$, which was shown to lack some epitopes present on the $140-\mathrm{kDa}$ CD21 molecule. This larger species also failed to bind to gp350/220. Sequence analysis of the CD21 transcript from these epithelial cells showed that it was identical to that derived from $B$ lymphocytes. Thus, precedent exists for the expression of the native $\mathrm{EBV}$ receptor, $\mathrm{CD} 21$, on the surface of nonlymphoid cells. The renal proximal tubule cell is another such example. Indeed, immunoreactivity for CD21 has been reported in epithelial tissue including the kidney, but the precise nephron segment had not been identified (8).

It is tempting to speculate that induction of interstitial nephritis by EBV is the consequence of a cellular immune response by infected proximal tubule cells, akin to that described in B lymphocytes. EBV-infected B lymphocytes express the virus-encoded latent membrane protein (LMP), which induces an HLA class I restricted cellular immune response (32). EBV also induces the expression of $\mathrm{CD} 21$ on lymphocytes that could further enhance the infectivity of target cells (33-35). In addition, agonistic antibodies directed against $\mathrm{CD} 21$ can activate cell cycle progression in $\mathrm{B}$ lymphocytes, thereby suggesting a role for CD21 in the activation of certain signaling pathways (36). EBV also upregulates the lymphocyte surface molecules CD54 (ICAM-1), LFA-1, and LFA-3 $(33,37)$. It is also a strong inducer of the expression of the lectin glycoprotein $\mathrm{CD} 23$, a multifunctional molecule involved in several aspects of lymphocyte biology including B cell growth stimulation, and it has been identified as a probable ligand for CD21 (38). To our knowledge, none of the aforementioned mechanisms have been explored in the setting of chronic interstitial nephritis. Such a mecha- nism would be analogous to that proposed to explain the relationship between the presence of EBV gene expression in the synovial cells of patients with rheumatoid arthritis (39). It would be of further interest to determine whether proximal tubule cells express LMP, and, if so, whether they can act as class I restricted targets of lysis by HLA-matched lymphocytes. A case report describing oliguric acute renal failure in a patient with infectious mononucleosis-associated interstitial nephritis is an example of what was likely an immune-mediated renal injury resulting from $\mathrm{CD} 8^{+} \mathrm{T}$ cells in an EBV-infected patient (40). In this case report, EBV was not detected in renal tissue by ISH.

An alternative explanation for our observation would be that the proximal tubule cell, damaged by some other process, presents a crippled barrier to EBV infection, and that the presence of the virus is consequent to this damage. Virions exposed to the renal tubule as a result of exposure to peripheral blood lymphocytes could enter the damaged tubular cell by some pathway independent of CD21. Subsequent viral gene expression delineated earlier could induce CD21 expression, possibly enhancing further viral infection. This amplified effect, resulting in viral infection, could be a secondary phenomenon. It is also possible that secondary induction of CD21, and the resulting enhancement of infection, may lead to an autocrine stimulatory loop that ultimately results in immune-mediated damage.

The literature regarding a potential role for EBV infection in renal disease is inconclusive. In this regard, perhaps the most comprehensive study was by Lee and Kjellstrand (41), who performed a retrospective evaluation of 128 patients with clinical and serologic evidence of infectious mononucleosis. Mild renal involvement as manifest by proteinuria and microscopically verifying hematuria was documented in approximately $16 \%$ of patients reviewed, and these features resolved over time. Acute renal failure has occasionally been documented by others $(40,42,43)$. A monocytic interstitial infiltrate is the more common finding on renal biopsy, but minimal glomerular changes have also been documented (44). Because EBV infection rarely involves significant disruption of renal function, renal biopsies are only performed under exceptional circumstances. In those instances where deteriorating renal function has demanded diagnostic intervention, EBV genome has been detected in infiltrating monocytes (42). To our knowledge, detection of the EBV genome in the proximal tubular epithelial cells of patients with any format of EBV infection has not been described previously. Thus, the link between acute or chronic EBV infection and chronic interstitial nephritis has, to date, not been established.

In summary, we document the presence of the EBV genome in proximal tubule epithelial cells of patients with chronic interstitial nephritis where no other explanation for the pathologic changes is forthcoming. The infected cells also express the receptor for the EBV virus. We speculate that infection of proximal tubule cells by 
EBV sets in motion a number of interrelated processes that culminate in an assault on the renal interstitium. Ongoing work will establish this causal link in the future.

\section{Acknowledgments}

The authors wish to thank Phyllis MacConnell, Angella Forde, Michele Margiotta, and Francie Gallery for their expert technical assistance. The expert secretarial assistance of Sherryl Krulik is gratefully acknowledged. This study was supported by National Institutes of Health grant DK-45605 (to E.P. Nord).

1. Mariette, X., Gozlan, J., Clerc, D., Bisson, M., and Marinet, F. 1991. Detection of Epstein-Barr virus DNA by in situ hybridization and polymerase chain reaction in salivary gland biopsy specimens from patients with Sjögren's syndrome. Am. J. Med. 90:286-294.

2. Epstein, M.A., and Achong, B.G. 1973. Various forms of Epstein-Barr virus infection in man: established facts and a general concept. Lancet. 2:836-839.

3. zurHausen, H., et al. 1970. EBV DNA in biopsies of Burkitt tumors and anaplastic carcinomas of the nasopharynx. Nature. 228:1056-1058.

4. deThe, G., et al. 1978. Epidemiological evidence for casual relationship between Epstein-Barr virus and Burkitt's lymphoma from Ugandan prospective study. Nature. 274:756-761.

5. Hanto, D., Sakamoto, K., Purtilo, D., Simmons, R., and Najarian, J. 1981. The Epstein-Barr virus in the pathogenesis of posttransplant lymphoproliferative disorders. Surgery. 90:204-213.

6. Fingeroth, J.D., et al. 1995. Epstein-Barr virus receptor of human B lymphocytes is the C3d receptor CR2. Proc. Natl. Acad. Sci. USA. 81:4510-4514

7. Birkenbach, M., Tong, X., Bradbury, L.E., Tedder, T.F., and Kieff, E. 1992. Characterization of an Epstein-Barr Virus receptor on human epithelial cells. J. Exp. Med. 176:1405-1414.

8. Timens, W., Boes, A., Vos, H., and Poppema, S. 1991. Tissue distribution of the $\mathrm{C} 3 \mathrm{~d} / \mathrm{EBV}$-receptor: $\mathrm{CD} 21$ monoclonal antibodies reactive with a variety of epithelial cells, medullary thymocytes, and peripheral T-cells. Histochemistry. 95:605-611.

9. Frappier, L., and O'Donnell, M. 1991. Epstein-Barr nuclear antigen 1 mediates a DNA loop within the latent replication origin of EpsteinBarr virus. Proc. Natl. Acad. Sci. USA. 88:10875-10879.

10. Hammerschmidt, W., and Sugden, B. 1989. Genetic analysis of immortalizing functions of Epstein-Barr virus in human B lymphocytes. Nature. 340:393-397.

11. Kaye, K.M., Izumi, K.M., and Kieff, E. 1994. Epstein-Barr virus latent membrane protein 1 is essential for B-lymphocyte growth transformation. Proc. Nat. Acad. Sci. USA. 90:9150-9154.

12. Mosialos, G., et al. 1995. The transforming protein LMP1 engages signaling proteins for the tumor necrosis factor receptor. Cell. 80:389-399.

13. Chow, L., Subramanian, S., Nuovo, G.J., Miller, F., and Nord, E.P. 1995. Endothelin receptor mRNA expression in renal medulla identified by in situ RT-PCR. Am. J. Physiol. 269:449-457.

14. Nuovo, G.J. 1990. Human papillomavirus DNA in genital tract lesions histologically negative for condylomata. Am. J. Surg. Pathol. 14:643-651.

15. Nuovo, G.J. 1991. Comparison of bouin solution and buffered formalin fixation on the detection rate by in situ hybridization of human papillomavirus DNA in genital tract lesions. J. Histotechnol. 14:13-17.

16. Sixbey, J.W., Nedrud, J.G., Raab-Traub, N., Hanes, R.A., and Pagano, J.S. 1984. Epstein-Barr virus replication in oropharyngeal epithelial cells. N. Engl. J. Med. 310:1225-1230.

17. Hilborne, L.H., Nieberg, R.K., Cheng, L., and Lewin, K.J. 1987. Direct in situ hybridization for rapid detection of cytomegalovirus in bronchoalveolar lavage. Am. J. Clin. Pathol. 87:766-769.

18. Hyypia, T. 1985. Detection of adenovirus in nasopharyngeal specimens by radioactive and nonradioactive DNA probes. J. Clin. Microbiol. 21:730-733.

19. Oliver, J., and MacDowell, M. 1957. The renal lesion in epidemic hemorrhagic fever. J. Clin. Invest. 36:199-222.

20. Saito, I., Servenius, B., Compton, T., and Fox, R.I. 1989. Detection of Epstein-Barr virus DNA by polymerase chain reaction in blood and tis- sue biopsies from patients with Sjögren's Syndrome. J. Exp. Med. 169:2191-2198.

21. Barnett, R.L., Ruffini, L., Hart, D., and Nord, E.P. 1994. Mechanism of endothelin activation of phospholipase $A_{2}$ in rat renal medullary interstitial cells. Am. J. Physiol. 266:46-56.

22. Aboolian, A., and Nord, E.P. 1988. Bradykinin increases cytosolic free $[\mathrm{Ca} 2+]$ in proximal tubule cells. Am. J. Physiol. 255:486-493.

23. Norman, J., et al. 1987. EGF-induced mitogenesis in proximal tubular cells: potentiation by angiotensin II. Am. J. Physiol. 253:299-309.

24. Nord, E.P., et al. 1986. Characteristics of the $\mathrm{Na}+-\mathrm{H}+$ antiporter in the intact renal proximal tubular cell. Am. J. Physiol. 25:539-550.

25. Detrisac, C.J., Sens, M.A., Garvin, A.J., Spicer, S.S., and Sems, D.A. 1981 Tissue culture of human kidney epithelial cells of proximal tubule origin. Kidney Int. 25:383-390.

26. Nadasdy, T., Laszik, Z., Blick, K.E., Johnson, B.L., and Silva, F.G. 1994 Tubular atrophy in the end-stage kidney: a lectin and immunohistochemical study. Hum. Pathol. 25:22-28.

27. Young, L.S., Dawson, C.W., Brown, K.W., and Rickinson, A.B. 1989. Identification of a human epithelial cell surface protein sharing an epitope with the C3d/Epstein-Barr virus receptor molecule of B lymphocytes. Int. J. Cancer. 43:786-794.

28. Silva, F.G., Nadasdy, T., and Laszik, Z. 1993. Immunohistochemical and lectin dissection of the human nephron in health and disease. Arch. Pathol. Lab. Med. 117:1233-1239.

29. Moore, M.D., Cooper, N.R., Tack, B.F., and Nemerow, G.R. 1987. Molecular cloning of the cDNA encoding the Epstein-Barr virus/C3d receptor (complement receptor type 2) of human B lymphocytes. Proc. Nat. Acad. Sci. USA. 84:9194-9198.

30. Fujisaku, A., et al. 1989. Genomic organization and polymorphisms of the human C3d/Epstein-Barr virus receptor. J. Biol. Chem. 264:2118-2125.

31. Weis, J.J., Toothaker, L.E., Smith, J.A., and Fearon, D.T. 1988. Structure of the human B lymphocyte receptor for C3d and the Epstein-Barr virus and relatedness to other members of the family of $\mathrm{C} 3 / \mathrm{C} 4$ binding proteins. J. Exp. Med. 167:1047-1066.

32. Rickinson, A.B., and Moss, D.J. 1997. Human cytotoxic T lymphocyte responses to Epstein-Barr virus infection. Annu. Rev. Immunol. 15:405-431.

33. Cordier, M., et al. 1990. Stable transfection of Epstein-Barr virus (EBV) nuclear antigen 2 in lymphoma cells containing the EBV P3HR1 genome induces expression of B-cell activation molecules CD21 and CD23. J. Virol. 64:1002-1013.

34. Wang, D., et al. 1988. Epstein-Barr virus latent infection membrane protein alters the human B-lymphocyte phenotype: deletion of the amino terminus abolishes activity. J. Virol. 62:4173-4184.

35. Larcher, C., et al. 1995. Expression of Epstein-Barr virus nuclear antigen-2 (EBNA2) induces CD21/CR2 on B and T cell lines and shedding of soluble CD21. Eur. J. Pharmacol. 25:1713-1719.

36. Frade, R., Barel, M., Ehlin-Henriksson, B., and Klein, G. 1985. Gp140, the C3d receptor of human B lymphocytes, is also the Epstein-Barr virus receptor. Proc. Natl. Acad. Sci. USA. 82:1490-1493.

37. Wang, F., et al. 1990. Epstein-Barr virus latent membrane protein (LMP1) and nuclear proteins 2 and 3C are effectors of phenotypic changes in B lymphocytes: EBNA-2 and LMP1 cooperatively induce CD23. J. Virol. 64:2309-2318.

38. Bonnefoy, J.Y., et al. 1997. Structure and functions of CD23. Int. Rev. Immunol. 16:113-128.

39. Takei, M., et al. 1997. Detection of Epstein-Barr virus-encoded small RNA 1 and latent membrane protein 1 in synovial lining cells from rheumatoid arthritis patients. Int. Immunol. 5:739-743.

40. Mayer, H.B., et al. 1996. Epstein-Barr virus-induced infectious mononucleosis complicated by acute renal failure: case report and review. Clin. Infect. Dis. 22:1009-1018.

41. Lee, S. and Kjellstrand, C.M. 1978. Renal disease in infectious mononucleosis. Clin. Nephrol. 9:236-240.

42. Muso, E., et al. 1993. Epstein-Barr virus genome-positive tubulo-interstitial nephritis associated with Kawasaki disease-like coronary aneurysms. Clin. Nephrol. 40:7-15.

43. L'Opez-Navidad, A., Domingo, P., L’Opez-Talavera, J.C., Rabella, N., and Verger, G. 1996. Epstein-Barr virus infection associated with interstitial nephritis and chronic fatigue. Scand. J. Infect. Dis. 28:185-187.

44. Nadasdy, T., et al. 1992. Epstein-Barr virus infection-associated renal disease: diagnostic use of molecular hybridization technology in patients with negative serology. J. Am. Soc. Nephrol. 2:1734-1742. 